\title{
CONCENTRACIÓN ECONÓMICA EN LA PROVINCIA DE TUNGURAHUA
}

\author{
VASILICA MARÍA MARGALINA ${ }^{1}$ \\ JUAN PABLO MARTÍNEZ MESÍAS ${ }^{2}$
}

\section{Índice Herfindahl}

\section{Hirschmann - HHI}

Las empresas activas en la provincia de Tungurahua generan un dinamismo económico, razón por la que se identifican variables tales como: ventas, exportaciones, número de empleados, población local, que se analizarán para determinar la concentración económica en el mercado en el periodo 2013-2014.

La información utilizada corresponde a fuentes secundarias oficiales y actualizadas del Directorio de Empresas y Establecimientos año 2014 del Instituto Nacional de Estadística y Censos - INEC. La estructura del análisis presenta los siguientes datos por cantón en la provincia de Tungurahua:

- Índice de concentración económica

- Ventas totales por sector económico

- Exportaciones por habitante

- Número de personas empleadas

\section{Índice de concentración económica por cantón}

La finalidad del análisis es determinar si en los distintos cantones de la provincia de Tungurahua existe nula, moderada o alta concentración económica. Entendiéndose ésta como la participación de los sectores de actividad en la generación de ventas en cada cantón de la provincia. Para tal fin, se calcula el Índice Herfindahl-Hirschmann - HHI por cantón.

El Índice Herfindahl-Hirschmann - HHI mide la concentración del mercado y se formula como la suma al cuadrado de la participación porcentual de la i-esima empresa en la industria (Gutiérrez-Rueda y Zamudio-Gómez, 2008). En la medición del HHI, se ha reemplazado a la empresa por el sector de actividad económica. La participación se estima en función del volumen de ventas de cada sector sobre el total de ventas de cada uno de los cantones, siendo su fórmula:

$$
H H I=\sum_{i=1}^{n}\left(\frac{X i}{X} * 100\right)^{2}
$$

\section{Donde:}

$\mathrm{HHI}$ = índice de concentración económica

$\mathrm{X}=$ ventas del sector de actividad económica

$X=$ ventas totales del cantón

Según los valores que alcanza el HHI (ver figura 1), se determina que un cantón tiene una concentración económica nula (1.500) si las ventas generadas en el cantón tienen la participación de todos los sectores de actividad económica; moderada (1.500-2.500) si las ventas se generan con la participación de una parte significativa de los sectores; y alta (2.500-10.000) si estas ventas se concentran en uno o dos sectores. En la figura 1 se presenta las características del índice HHI:

${ }^{1}$ Doctora en Economía de Empresas- Docente de la Facultad de Contabilidad y Auditoría e investigadora del Observatorio Económico y Social de Tungurahua -UTA

2Economista, Magíster en Administración de Empresas mención Planeación - Docente de la Facultad de Contabilidad y Auditoría e investigador del Observatorio Económico y Social de Tungurahua -UTA
Figura 1. Índice de concentración económica HHI

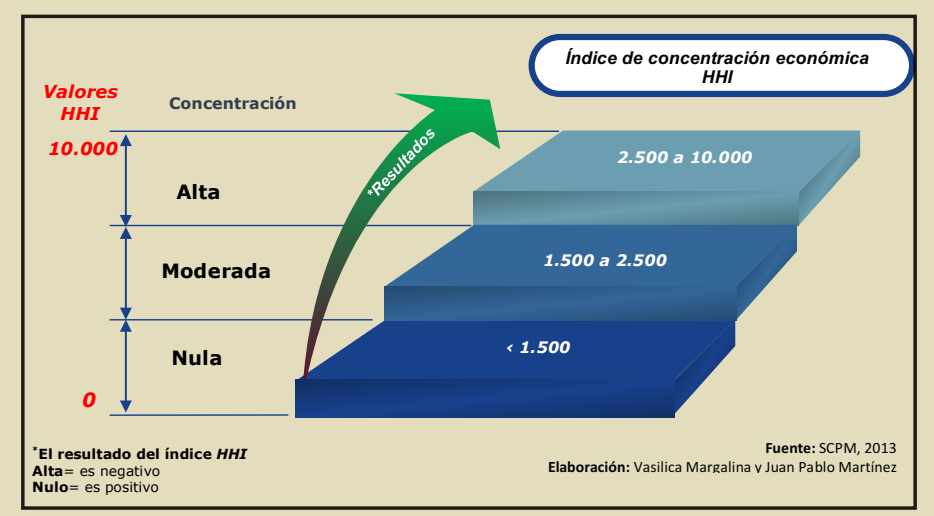

La información con respecto a las ventas generadas por los sectores de actividad económica en función de cada uno de los cantones se describe en la tabla 1.

\section{Tabla 1. Ventas por sector económico, según cantón en la Provincia de Tungurahua Periodo 2014}

\begin{tabular}{|c|c|c|c|c|c|c|c|c|}
\hline $\begin{array}{r}\text { Sector } \\
\text { económico } \\
\text { Cantón }\end{array}$ & & $\begin{array}{l}\text { Agricultura, } \\
\text { ganaderia, } \\
\text { vicultura y pesca }\end{array}$ & Comercio & Construcción & $\begin{array}{c}\text { Explotación de } \\
\text { Minas y } \\
\text { Canteras }\end{array}$ & $\begin{array}{l}\text { Industrias } \\
\text { Manufactureras }\end{array}$ & Servicios & Total \\
\hline Ambato & $\$$ & $72.677 .189,00$ & $\$ 1.552 .081 .838,00$ & $\$ 59.908 .776,00$ & $\$ 3.059 .896,00$ & $\$$ \$641.564.521,00 & $\$ 537.692 .500,00$ & $\$ 2.866 .984 .720,00$ \\
\hline Baños & $\$$ & $3.730 .732,00$ & S $\quad 27.797 .878,00$ & $\$ 612.506,00$ & $\$ \quad 43.277,00$ & \$ $40.284 .605,00$ & \$ $19.964 .933,00$ & \$ $92.433 .931,00$ \\
\hline Cevallos & $\$$ & $1.911 .158,00$ & \$ $11.735 .680,00$ & & . & $\$ 2.660 .876,00$ & $\$ 3.543 .240,00$ & \$ $19.850 .954,00$ \\
\hline Mocha & $\$$ & $1.002 .355,00$ & $\begin{array}{l}\$ \\
6.839 .210,00\end{array}$ & - & . & $91.778,00$ & $\$ \quad 1.215 .286,00$ & $9.148 .629,0 \mathrm{C}$ \\
\hline Patate & $\$$ & $6.988 .710,00$ & $\$ \quad 9.441 .580,00$ & $\$ \quad 90.051,00$ & - & $\$ 1.318 .696,00$ & \$ $3.917 .960,00$ & \$ $\quad 21.756 .997,00$ \\
\hline Quero & $\$$ & $287.124,00$ & $\begin{array}{l}\text { \$ } \quad 15.419 .366,00 \\
\end{array}$ & \$ $157.146,00$ & - & $\begin{array}{l}\$ 2.694 .429,00 \\
0\end{array}$ & $\$ 4.807 .475,00$ & $\$ \quad 23.365 .540,00$ \\
\hline Pelileo & $\$$ & $49.634 .772,00$ & \$ $102.569 .933,00$ & $\$ 974.865,00$ & $\$ 271.900,00$ & \$ 54.735.626,00 & $\$ 12.020 .331,00$ & \$ $220.207 .427,00$ \\
\hline Pillaro & $\$$ & $9.704 .212,00$ & \$ 25.644.607,00 & $\$ 1.023 .425,00$ & $\cdot$ & \$ $8.899 .720,00$ & \$ $8.363 .646,00$ & $\$ \quad 53.635 .610,00$ \\
\hline Tisaleo & & & \$ $8.011 .629,00$ & $\$ 586.377,00$ & . & \$ $1.832 .679,00$ & \$ $1.498 .738,00$ & \$ $\quad 11.929 .423,00$ \\
\hline Total & $\$$ & 145.936.252,00 & $\$ 1.759 .541 .721,00$ & $\$ 63.353 .146,00$ & $\$ 3.375 .073,00$ & $\$ 754.082 .930,00$ & $\$ 593.024 .109,00$ & $\$ 3.319 .313 .231,00$ \\
\hline & & & & & & & Directroind & presas 2014. JNE \\
\hline
\end{tabular}

Se evidencia que, en general, las ventas del sector comercio predominan en la provincia de Tungurahua, exceptuando los sectores de construcción y explotación de minas y canteras, que no registran información en todos los cantones.

En base a la tabla 1., se representa el índice HHI (figura 2), en la cual se muestra una fuerte concentración económica en todos los cantones. Según datos del año 2014, la concentración más alta la tiene Mocha $(\mathrm{HHI}$ de 5.916), Quero $(\mathrm{HHI}$ de 4.943) y Tisaleo $(\mathrm{HHI}$ de 4.908. En cambio, la concentración más baja se registra en los cantones Píllaro (HHI de 3.177), Baños (un HHI de 3.337) y Ambato $(\mathrm{HHI}$ de 3.774).

En el año 2014, la concentración económica respecto al año 2013 se incrementa en la mayoría de los cantones, con excepción de Baños (HHI de 3.432, en 2013) y Ambato (HHI de 3.878, en 2013). En general, el sector Comercio acapara el mayor porcentaje de las ventas totales en la provincia de Tungurahua. Baños es el único cantón donde el mayor porcentaje está representado por el sector de Industrias Manufactureras. 


\section{Figura 2. Concentración económica en los cantones de la Provincia de Tungurahua periodo 2013-2014}

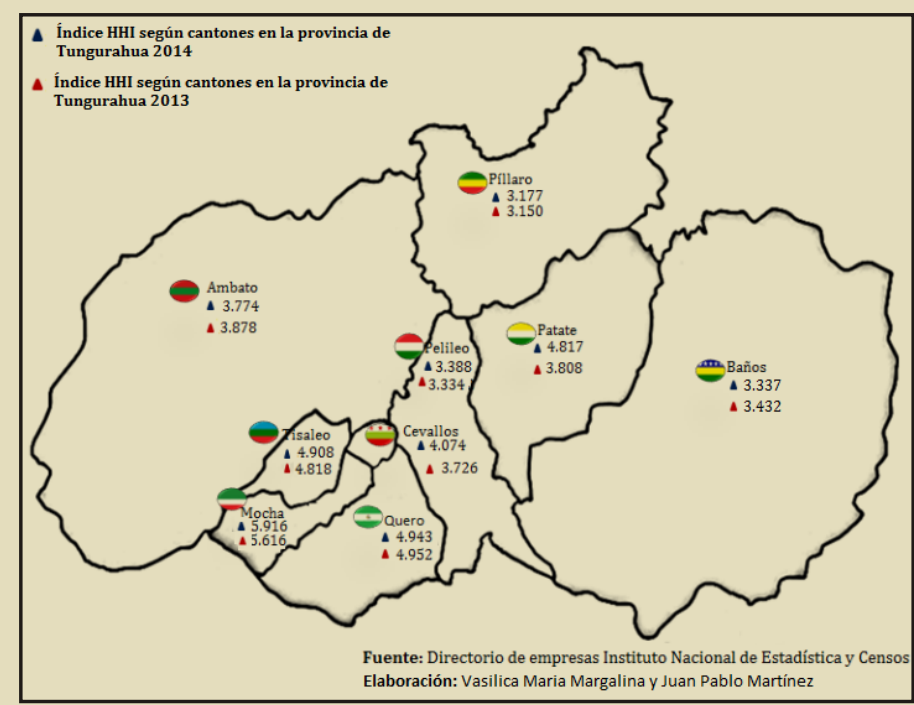

Cabe mencionar que, la base de datos del Directorio año 2014, no presenta información sobre el número de empresas activas, esto hace que no se pueda establecer un análisis detallado del comportamiento de las ventas y la concentración económica según el número de empresas.

\section{Ventas y exportaciones por habitante en los cantones de la provincia}

En el año 2014, las ventas totales de las empresas activas en la provincia de Tungurahua registraron un crecimiento del 9\% en comparación con el año 2013, alcanzando un volumen de USD 3.319'313.231. La mayor cantidad de ventas (figura 3) se registra en el cantón Ambato, con USD 2.866'984.720 (+8\%); seguido por Pelileo, con USD 220.207.427 (+13\%); y, Baños con USD 92.433 .931 (+20\%). Según datos del INEC (2014), las ventas han aumentado en todos los cantones de la provincia. El mayor crecimiento de las ventas se observan en Patate (31\%), Tisaleo (29\%) y Mocha (23\%).

Las exportaciones totales por habitante (Figura 3) en la Provincia de Tungurahua disminuyeron 14\% en el año 2014, de USD171 a USD147, destaca el cantón Pelileo con USD234 por habitante y, además, es el único que ha registrado crecimiento de este indicador en el año 2014 frente al periodo anterior. El cantón Ambato, registra una significativa disminución de USD224 a USD181 que corresponde al 19\%.

El indicador exportaciones per cápita, analiza las exportaciones por habitante. Éste compara relativamente el monto de comercio que corresponde a cada persona y permite determinar el nivel de internacionalización de la economía. (Durán-Lima, 2012).

Para calcular este indicador, se menciona que el INEC divulga todos los años, datos de exportaciones, pero el registro completo, sólo incluye a los cantones: Ambato, Pelileo y Patate. Para el resto de cantones, la información es irregular, es decir, unos años muestran datos y otros no.

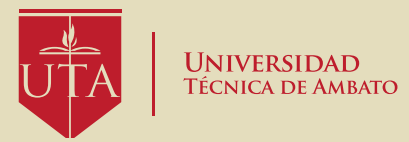

Figura 3. Ventas totales y exportaciones por habitante, según Empresas activas Provincia de Tungurahua Periodo 2013-2014

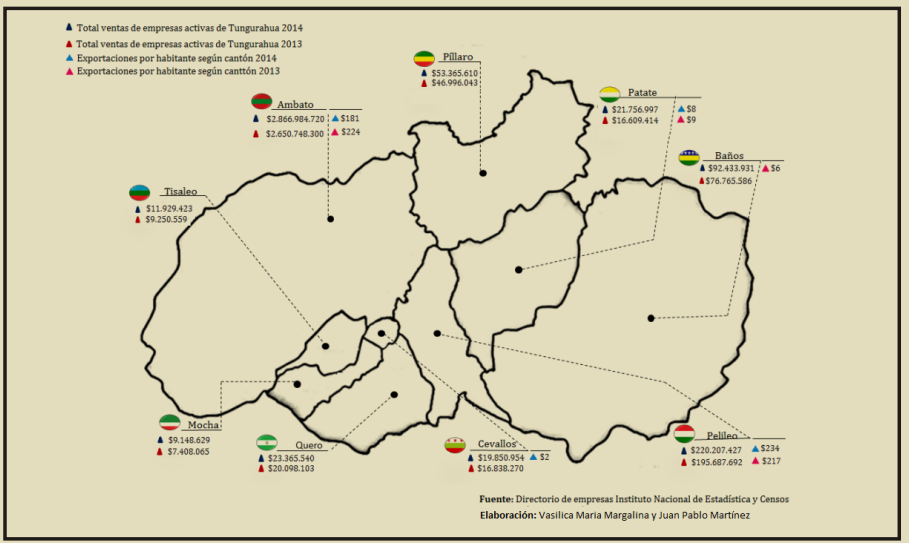

En el año 2014, el análisis (figura 4) muestra que el cantón con mayor número de personas empleadas es Ambato (78.561), con un crecimiento del 4\% en comparación al año 2013. Le sigue con una notable diferencia, Pelileo con 6.000 personas empleadas y Baños con 4.399. Mientras que los de menor representatividad en cuanto a la fuerza laboral empleada son: Mocha (543), Tisaleo (592) y Patate (780).

En general, el empleo en los cantones de Tungurahua aumentó en el año 2014 con respecto al año anterior, como por ejemplo, Quero registra un crecimiento significativo del $45 \%$, de 774 a 1.122 personas empleadas. Otro escenario se observa en Cevallos, con un descenso del $1 \%$.

\section{Figura 4. Número de personas empleadas, según cantones Provincia de Tungurahua Periodo 2013-2014}

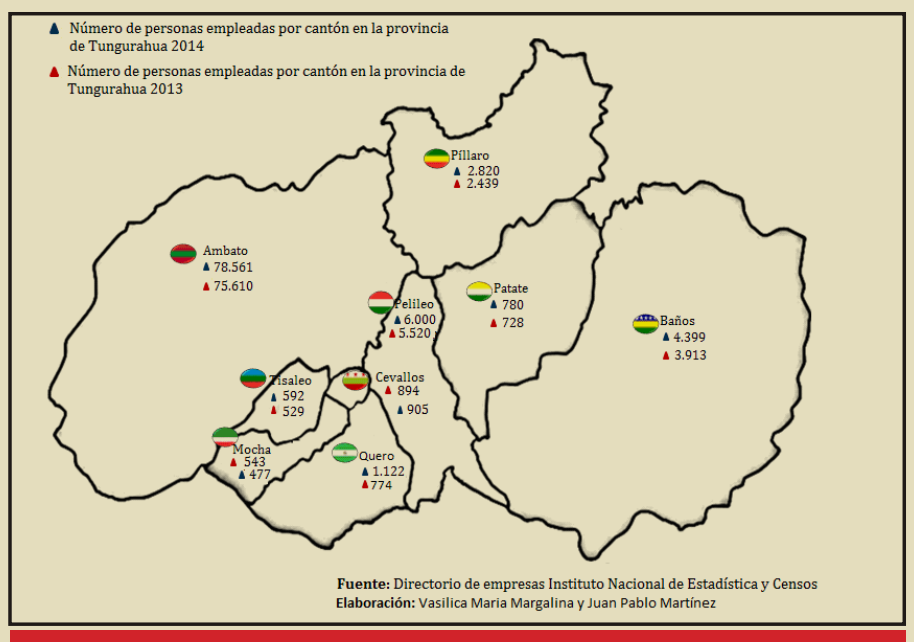

Referencias:

-Durán-Lima, J. (2012). Aplicaciones del Observatorio de Comercio e Integración Centroamericana. Caso1. Disponible en: http://www.cepal.org/sites/default/files/events/ files/caso_01.pdf

-Gutiérrez-Rueda, J. y Zamudio-Gómez; N. (2008). Reporte de Estabilidad Financiera. Medidas de concentración y competencia. Disponible en: http://www.banrep.gov.co/ docum/Lectura_finanzas/pdf/medidas.pdf

-NEC (10 enero, 2013). INEC presenta sus proyecciones poblacionales cantonales. Disponible en: http://www.ecuadorencifras.gob.ec/inec-presenta-sus-proyecciones-poblacionales-cantonales/

-SCPM (2013). Indicadores de concentración. Disponible en: http://scpm.gob.ec/ wp-content/uploads/2013/02/FORMULARIO-GESTION4.pdf 